\title{
Fibromialgia e Estresse Infeccioso: Possíveis Associações Entre a Síndrome de Fibromialgia e Infecções Viróticas Crônicas ${ }^{(*)}$
}

\section{Fibromyalgia and Infectious Stress: Possible Associations between Fibromyalgia Syndrome and Chronic Viral Infections}

\author{
Luiz Severiano Ribeiro ${ }^{(1)}$, Fernando Augusto Proietti ${ }^{(2)}$
}

\section{RESUMO}

As infecções viróticas crônicas são implicadas como um possível fator determinante no estudo da etiopatogenia da fibromialgia. As premissas para tanto interesse derivam do fato de que compartilham de manifestações clínicas comuns, especialmente as de dor musculoesquelética disseminada e fadiga. Apesar dos resultados discordantes das pesquisas, o interesse é crescente por essa área, à medida que novos estudos conseguem replicar os resultados de seus antecessores, como no caso da provável associação entre a fibromialgia e a infecção crônica pelo vírus $\mathrm{C}$ da hepatite. Com o objetivo de apresentar um painel de revisão sobre esses estudos, os autores compilaram vários artigos da literatura indexada, utilizando como fonte de dados o Medline e o Lilacs.

Palavras-chave: fibromialgia, virose.

\section{INTRODUÇÃO}

A fibromialgia é definida como uma síndrome de dor musculoesquelética crônica difusa associada à presença de sensibilidade exacerbada à palpação de determinados sítios dolorosos, os chamados pontos dolorosos $\left(\right.$ tender points) ${ }^{(1)}$.

Além da dor e dos pontos dolorosos, são comuns os sintomas de irregularidades do sono (sono não-restaurador), fadiga e rigidez matinal. Também se fazem presentes, embora menos freqüientes, as parestesias, as cefaléias, a depressão, a ansiedade, o cólon irritável, os sintomas referentes a boca e/ou olhos secos (sintomas sicca) e o fenômeno de Raynaud ${ }^{(1)}$.

\begin{abstract}
Chronic viruses are implicated in the etiopathogenesis of fibromyalgia syndrome. The increasing interest in research is derived from the clinical manifestations shared by both conditions, mainly the musculoskeletal pain and fatigue. However, in spite of intense research no viruses have unequivocally been identified as directly causing fibromyalgia. Exception may be the probable association between fibromyalgia and hepatitis $C$ virus chronic infection. The authors present a literature review in order to approach the presumed associations or lack of associations between fibromyalgia and viral chronic infections. This compilation was done using Medline and Lilacs databases.
\end{abstract}

Keywords: fibromyalgia, viruse.

A dor musculoesquelética crônica é um achado comum na população geral, podendo apresentar-se como regional ou difusa $^{(2-4)}$. O seu mecanismo gerador pode ser explicado por uma alteração no processamento central da dor em nível espinhal. As bases fisiopatológicas para a ocorrência de tal fenômeno repousam sobre o mecanismo de geração da dor não-nociceptiva (DNN), definida como a experiência dolorosa resultante da estimulação de neurônios não relacionados com a dor (não-nociceptivos) na coluna espinhal. No nível molecular, estudos têm apontado o papel crucial de aminoácidos (p.ex. a glutamina) e de neuropeptídeos (p.ex. a substância P) no processo de sensibilização central.

* Trabalho realizado no Serviço de Reumatologia do Hospital Governador Israel Pinheiro (IPSEMG), Belo Horizonte-MG, Brasil, e no Departamento de Medicina Preventiva e Social, Faculdade de Medicina, Universidade Federal de Minas Gerais (UFMG), Belo Horizonte-MG, Brasil. Recebido em 05/08/2004. Aprovado, após revisão, em 18/11/2004.

1. Reumatologista do IPSEMG; doutorando em Saúde Pública, área de concentração em Epidemiologia.

2. Professor adjunto de Epidemiologia e Saúde Publica da Faculdade de Medicina da UFMG.

Endereço para correspondência: Luiz Severiano Ribeiro. Rua Professor Arduíno Bolivar, 336/04, Santo Antônio, Belo Horizonte, MG, Brasil, CEP 30350-140. E-mail: luizseveriano@brfree.com.br 
Os níveis elevados de substância $\mathrm{P}$ detectados nos pacientes com fibromialgia estão de acordo com a teoria de sensibilização central na patogênese da síndrome. A percepção da dor é também regulada por vias inibitórias descendentes espinhais - os chamados tratos espinhais antinociceptivos descendentes - sendo aqui crucial o papel da serotonina, o mais importante neurotransmissor do sistema descendente inibitório. Experimentalmente podem ser demonstrados níveis reduzidos de serotonina e de seu precursor, o triptofano, nesses estados de dor crônica. É como uma parte do espectro maior da chamada dor musculoesquelética crônica que emerge a fibromialgia, e assim deve ser considerada para o seu estudo $^{(5-8)}$ (Figuras 1 e 2).

Apesar dos avanços no conhecimento dos mecanismos fisiopatológicos da dor crônica, as causas da fibromialgia, com seus sintomas típicos (sono não-restaurador, fadiga e rigidez matinal) e associados (cefaléias, parestesias, cólon

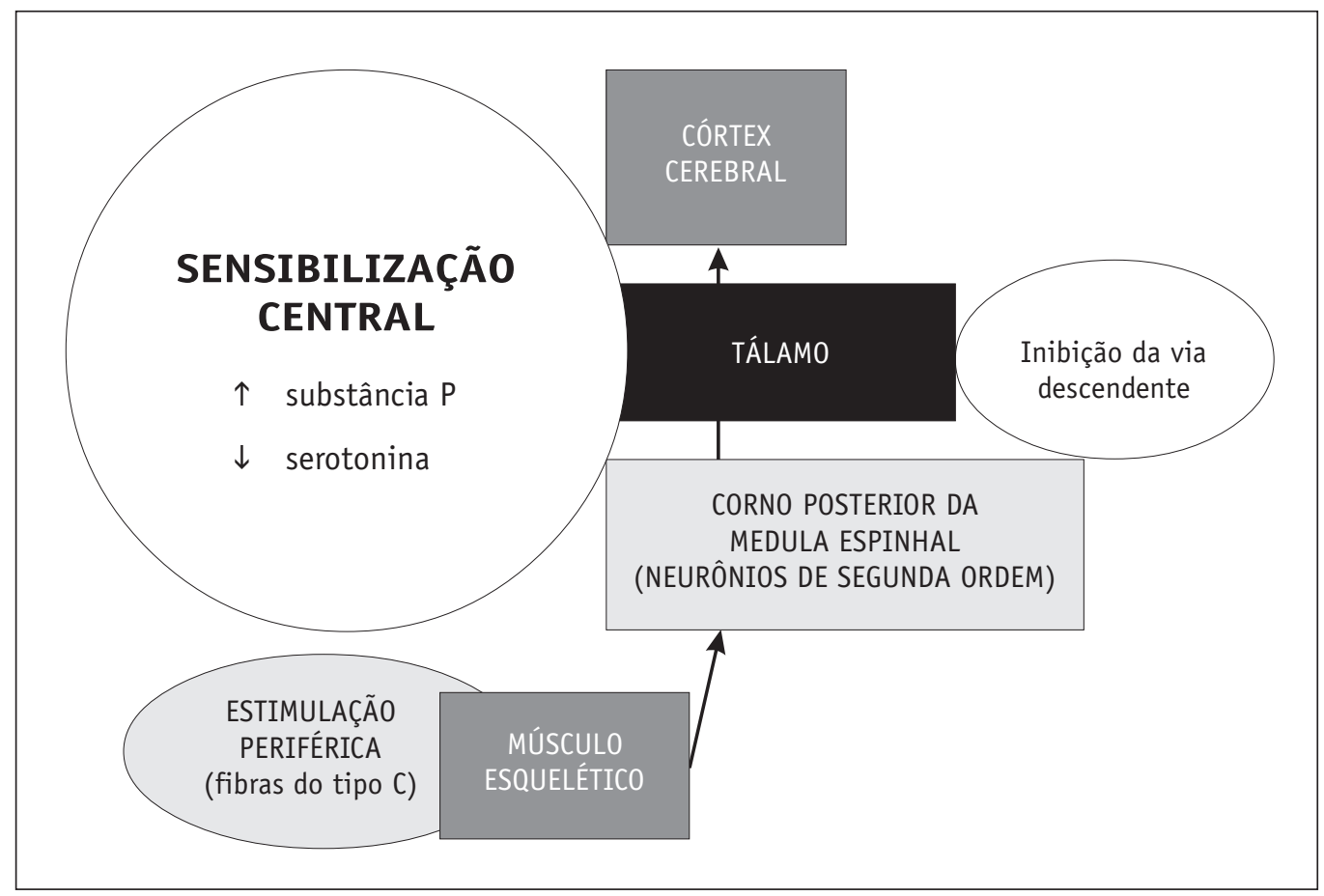

FIGURA 1 - Dor não-nociceptiva $(\mathrm{DNN})^{(5)}$.

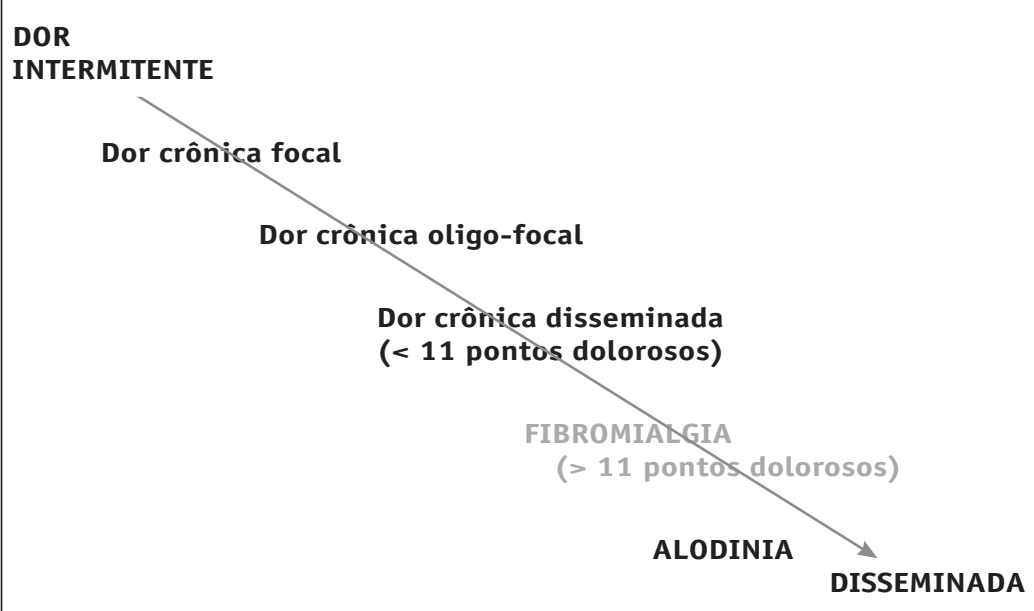

Rev Bras Reumatol, v. 45, n. 1, p. 20-9, jan./fev., 2005
Figura 2 - Espectro da dor musculoesquelética crônica (Modificado de Bennett) ${ }^{(5)}$. 
irritável, sintomas sicca, alterações do humor, fenômeno de Raynaud dentre outros), permanecem por ser esclarecidas. Muitos pacientes referem o início de seus sintomas associado ao estresse físico e/ou estresse emocional. A síndrome ocorre associada em 20\% a 35\% dos pacientes com desordens auto-imunes, como lúpus eritematoso sistêmico e artrite reumatóide ${ }^{(5,9-11)}$.

Os sintomas de mialgia generalizada e fadiga que comumente acompanham doenças viróticas tornam essa hipótese etiológica bastante plausível, sendo esse o motivo de nosso artigo de revisão.

É fato, no entanto, que a maioria dos indivíduos expostos a possíveis fatores determinantes, como os acima relacionados, não desenvolverão fibromialgia. Dessa maneira, aqueles que virão a se tornar fibromiálgicos são tanto geneticamente predispostos, quanto poderão vir a ser expostos a fatores ambientais causadores da síndrome ${ }^{(5)}$.

Na prática clínica diária, infecção e inflamação (p.ex. infecções virais e lúpus eritematoso sistêmico) são freqüentemente associadas à dor. Experimentos em animais tentam desvendar possíveis mecanismos responsáveis pela sensibi- lização do sistema nervoso central e geração da dor musculoesquelética, como descrita acima, nessas circunstâncias ${ }^{(5)}$ (Figura 3).

Embora as doenças virais em humanos tenham sido reconhecidas desde a Antigüidade e muitas ainda são continuamente descobertas nos dias atuais, apenas nos primórdios do século XX as primeiras viroses começaram a ser identificadas. As descobertas evoluíram ao longo de todo o século, culminando com a definição, em um nível atômico de resolução, da estrutura dos componentes das partículas virais, além da seqüência completa do genoma de muitos vírus. Permanece como um dos grandes desafios da virologia contemporânea a compreensão dos intrincados mecanismos de interação entre a partícula viral e as célulasalvo de hospedeiros vivos para produzir doença ${ }^{(12)}$.

As viroses têm sido implicadas na patogênese de muitas desordens reumáticas inflamatórias e auto-imunes ${ }^{(13)}$, bem como é crescente o interesse pelo estudo das mesmas como possíveis fatores determinantes da fibromialgia, especialmente no que se refere às associações encontradas entre a infecção crônica pelo vírus $\mathrm{C}$ da hepatite e fibromialgia ${ }^{(14-19)}$.

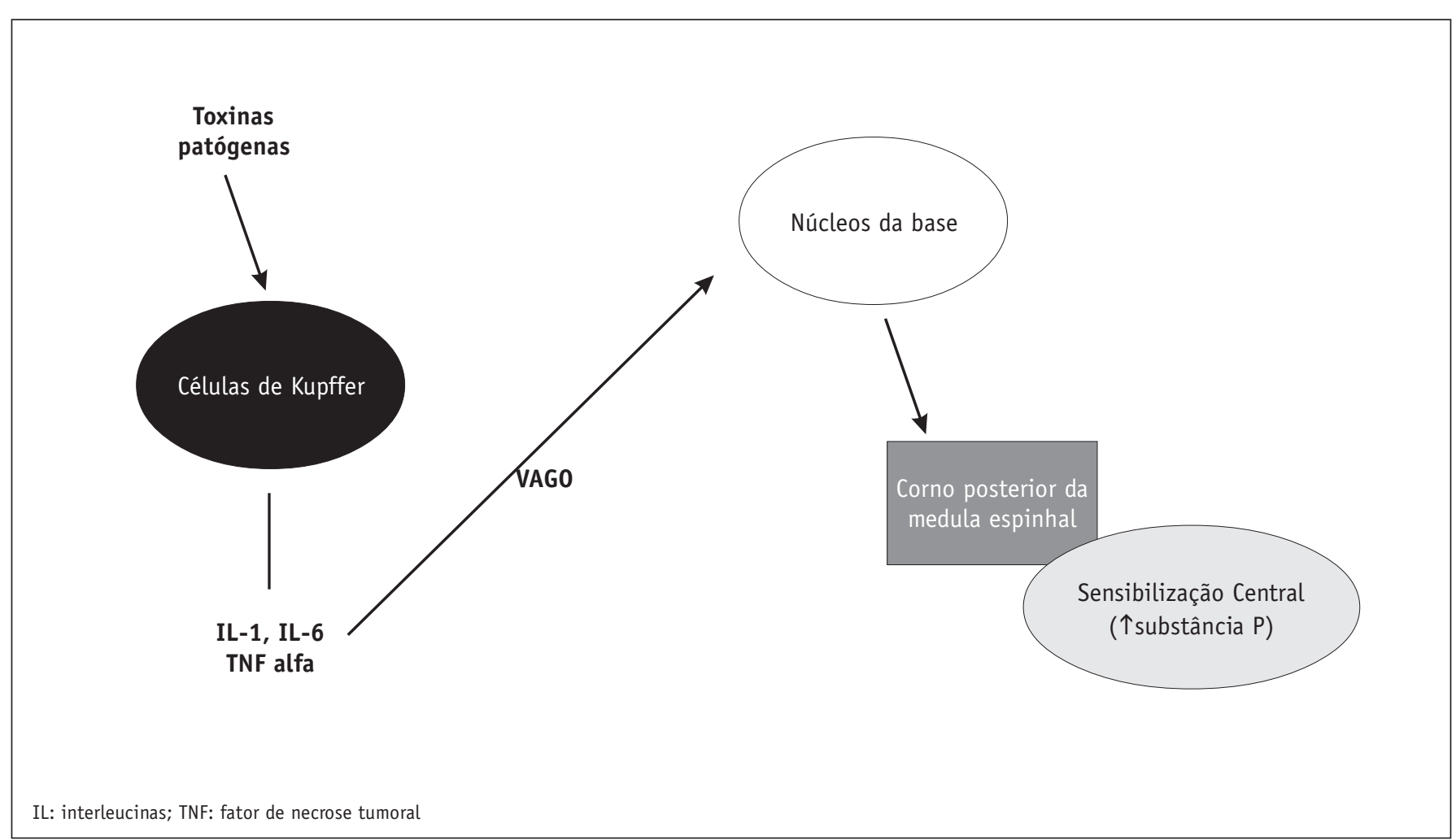

Figura 3 - Modelo murino de sensibilização central após exposição a toxinas produzidas por infecções virais (Modificado de Bennett) ${ }^{(5)}$. 
Dentre os mecanismos propostos para o envolvimento das viroses na etiopatogênese de doenças reumáticas, destacam-se: a) o efeito tóxico direto na célula-alvo; b) alterações da membrana celular dependentes da presença do vírus; c) formação de complexos imunes; d) mimetismo molecular; e) formação de superantígenos; f) modificação da resposta imune ${ }^{(13)}$.

O presente artigo se propõe revisar a literatura indexada da base de dados Medline e Lilacs dos trabalhos que descreveram a ocorrência, ou não, de uma associação entre a fibromialgia e infecções viróticas crônicas.

Será referida, em muitos estudos compilados, a síndrome da fadiga crônica, uma condição clínica relacionada à FM, pelo fato de, na grande maioria das vezes, os pacientes diagnosticados com essa síndrome também apresentarem critérios diagnósticos para a FM. A síndrome da fadiga crônica é definida pelo início agudo de fadiga, após um evento sugestivo de um processo infeccioso, cursando com dor musculoesquelética crônica, alterações do sono (sono não-restaurador), depressão e/ou ansiedade. Dentre os termos sinônimos utilizados ao longo dos anos para a sua designação, incluem-se: febrícula, neurastenia, infecção crônica pelo Epstein-Barr, dentre outros ${ }^{(1)}$.

No entanto, os artigos que trataram exclusivamente da síndrome da fadiga crônica foram, quando muito, apenas mencionados, pelo conteúdo da discussão, em sua relevância para a associação com a FM, por isso o termo não foi empregado como palavra-chave da pesquisa.

\section{VÍRUS DE EPSTEIN-BARR}

$\mathrm{O}$ vírus de Epstein-Barr(EB), pertencente à família Herpesviridae, possui um núcleo constituído de DNA e uma cápsula de simetria icosaédrica composta por 162 capsômeros $^{(20)}$.

$\mathrm{O}$ vírus infecta exclusivamente células $\mathrm{B}$ e determina infecções denominadas produtivas, quando há propagação de formas infectantes pelas células acometidas, bem como infecções não-produtivas, quando o genoma viral está presente sob a forma latente, incorporado ao DNA da célula do hospedeiro. O vírus EB pode, assim, determinar infecções agudas, como a mononucleose infecciosa, até quadros crônicos, como a infecção crônica pelo vírus EB ou "mononucleose crônica", além de neoplasias, como o linfoma de Burkitt e o carcinoma nasofaríngeo ${ }^{(20-21)}$.

A infecção crônica pelo vírus EB ocorre com evidências sorológicas de uma infecção latente recidivada, e clinicamente se apresenta com fadiga, mialgias, artralgias, cefaléias recorrentes e distúrbios do sono, representantes das características similares àquelas observadas na fibromialgia, além de dor de garganta, adenopatia, febre baixa, tosse crônica e história de alergias $^{(21)}$.

Buchwald et al., em 1987, avaliaram 50 pacientes com o diagnóstico de fibromialgia, que também apresentavam sintomas semelhantes aos da infecção crônica pelo EB: história de alergias (64\%), dor de garganta (54\%), tosse crônica (40\%), adenopatia (32\%) e febre baixa recorrente (28\%). Quando comparados a controles sadios e "não-sadios" (representados por pacientes com pelo menos uma doença crônica, exceto doenças reumáticas sistêmicas, insuficiência cardíaca ou renal) emparelhados por sexo e idade, esses pacientes não apresentaram títulos significativamente diferentes daqueles dos grupos controles para os anticorpos anti-VCA (viral capsid antigen) IgM e IgG (indicativo de infecção crônica), anti-EA (early antigen) IgG (marcador de infecção prévia) e anti-EBNA (Epstein-Barr nuclear antigen, presente em portadores sadios) $)^{(21)}$.

Whelton, Salit e Moldofsky, em 1992, também não encontraram diferenças estatísticas para os títulos de antiVCA e anti-EBNA entre 14 pacientes com síndrome da fadiga crônica e 12 controles sadios ${ }^{(22)}$.

No Brasil, em 1992, Feldman et al. avaliaram a presença do anti-VCA IgG em 88 fibromiálgicos comparados a 52 controles reumatológicos. Títulos iguais ou superiores a 1/640 foram encontrados em 44 (50\%) pacientes fibromiálgicos e em apenas ${ }^{13}$ controles (25\%), sugerindo uma possível associação entre a infecção crônica pelo vírus EB e a síndrome de fibromialgia ${ }^{(23)}$.

\section{PARVOVÍRUS B 19}

Único membro da família Parvoviridae com a capacidade de infectar o homem, o parvovírus B 19 é o menor vírus contendo DNA de hélice simples e um capsídeo icosaédrico não recoberto por envelope.

Descoberto acidentalmente, em 1975, por Cossart et al., quando pesquisavam o antígeno de superfície da hepatite B em doadores de sangue assintomáticos, recebeu essa denominação devido ao número da bolsa de sangue em que foi detectado ${ }^{(24)}$.

Apresenta um tropismo para as células progenitoras de eritróides, e outras células do sistema hematológico, como neutrófilos e plaquetas, podem ser igualmente afetadas ${ }^{(24)}$. Em hospedeiros imunocompetentes está implicado como o agente causador do eritema infeccioso, a quinta doença da infância, e ao desenvolvimento de uma artropatia, mais 
freqüentemente observada em adultos, de evolução variável com artralgias e artrite franca, que pode mimetizar um quadro de artrite reumatóide ${ }^{(25)}$. A infecção crônica em hospedeiros imunocomprometidos, como em pacientes com a síndrome da imunodeficiência adquirida (SIDA) e naqueles com anemia hemolítica, pode cursar com quadros graves de supressão da medula óssea.

Em 1991, Leventhal et al., pela primeira vez na literatura, relatam três casos de desenvolvimento dos sintomas de FM após infecção aguda pelo parvovírus B $19^{(26)}$.

Em 1993, Berg et al. avaliaram a presença de anticorpos anti-B 19 IgG e IgM em 26 mulheres com o diagnóstico de FM, das quais 15 relacionavam o início dos sintomas da síndrome associado a um quadro prévio suspeito de infecção virótica, e 11 sem um quadro prodrômico relacionado. Compararam os achados àqueles pesquisados em 26 controles sadios do sexo feminino. A PCR (polymerase chain reaction) para detecção de viremia persistente foi também avaliada. Os autores não encontraram qualquer associação da infecção prévia pelo parvovírus B 19 (anti-B 19 IgG) entre fibromiálgicas com e sem história prévia suspeita de infecção. Nenhuma das pacientes ou controles apresentavam evidências de infecção recente (anti-B 19 IgM). Também não foram encontradas evidências para viremia persistente em pacientes e controles pela PCR ${ }^{(25)}$.

Branco et al., em 1994, realizaram um estudo para a comparação dos títulos do anti-B 19 IgG em 52 fibromiálgicos (3 homens e 49 mulheres) e 39 controles (17 homens e 22 mulheres). Essa análise detecta uma maior prevalência de títulos elevados do anti-B 19 IgG no sexo feminino tanto em fibromiálgicas quanto nos controles, não sendo encontrada uma diferença estatística entre os dois grupos quando comparados ${ }^{(27)}$.

Em 1995, outro estudo procura estabelecer uma correlação entre a parvovirose e a síndrome da fadiga crônica em 7 pacientes com esse diagnóstico, que foram selecionados devido à presença de alterações hematológicas suspeitas de disfunção da medula óssea. As análises incluíram a pesquisa de anticorpos anti-B 19 IgG e IgM, PCR do soro e da medula óssea, além de biópsia de medula óssea. Os resultados foram negativos para a presença de infecção pelo parvovírus B 19 nesse grupo seleto de pacientes ${ }^{(28)}$.

\section{VÍRUS COXSACKIE B}

O gênero enterovírus, pertencente à família Piconaviridae, inclui mais de 70 sorotipos, entre os quais os rinovírus (10 tipos), os poliovírus (3 tipos), os vírus Coxsackie (24 do grupo A e 6 do grupo B) e 34 tipos do vírus ECHO (Enteric Cytophatogenic Human Orphan viruses) ${ }^{(29)}$.

Os vírus Coxsackie são constituídos de RNA e desprovidos de envoltório. Morfologicamente apresentam-se como corpúsculos esféricos, geralmente agrupados, às vezes formando grupamentos de aspecto hexagonal ou de pseudocristais ${ }^{(29)}$.

Apresentam tropismo para as células musculares e estão implicados como agentes causais de um grande número de desordens musculares, como a doença de Bornholm (caracterizada principalmente por febre e dores musculares), miocardite aguda e, em modelos murinos, por polimiosite $\operatorname{aguda}^{(29,30)}$.

Evidências de infecção crônica em humanos têm sido acumuladas pela utilização de ensaios sorológicos e técnicas de hibridização in situ do RNA viral ${ }^{(30)}$.

Em 1989, Nash et al. descrevem o caso de uma mulher que evolui para um quadro clínico consistente com o diagnóstico de FM (dor muscular generalizada persistente e presença de 12 pontos dolorosos), após tratamento para infecção aguda pelo Coxsackie B2 (confirmado na presença de anticorpos IgM específicos para o vírus em altos títulos). Os sintomas de apresentação do quadro agudo incluíam febre, faringite, mialgia, poliartrite que comprometia joelhos, punhos, pequenas articulações das mãos e dos pés, além de máculas eritematosas distribuídas pelo tronco, braços e coxas. Os sintomas referentes a mialgia, sono nãorestaurador, fadiga e rigidez matinal persistiram na vigência de títulos elevados dos anticorpos IgM anti-Coxsackie B2, durante os quatro anos de acompanhamento relatados ${ }^{(30)}$.

Em 1996, Buchwald et al. avaliaram a soroprevalência dos anticorpos anti-Coxsackie tipos 1 a 6 em 548 pacientes com fadiga crônica, divididos em subgrupos de acordo com os critérios para a síndrome da fadiga crônica, FM e desordens psiquiátricas. Não foram detectadas diferenças entre os subgrupos para a soropositividade desses anticorpos, tampouco entre o grupo como um todo e controles sadios ${ }^{(31)}$.

Em 2001, Wittrup et al. avaliaram dois grupos de mulheres fibromiálgicas, divididos, de acordo com o início dos sintomas da síndrome, em agudo (19 pacientes) e crônico (20 pacientes). Anticorpos IgM contra enteroviroses foram detectados em 50\% do grupo de início agudo e em $15 \%$ do grupo crônico $(\mathrm{p}<0,04)$. Não há menção aos subtipos de enterovírus estudados ${ }^{(32)}$.

\section{VÍRUS DA IMUNODEFICIÊNCIA HUMANA}

O vírus da imunodeficiência humana (HIV) é um retrovírus do grupo dos lentivírus pertencentes à família Retroviridae. 
Os retrovírus constituem uma grande família de vírus compostos por RNA, tendo como vantagens para a sua sobrevivência a sua grande diversidade genética e o fato de que seu ciclo de replicação envolve um estágio intermediário de transcrição do RNA viral em DNA linear de duplahélice, com conseqüente integração de seu material genético ao genoma do hospedeiro, o que lhes confere a capacidade de permanecerem em estado de latência. O fato de apresentar um tropismo para células $\mathrm{T} \mathrm{CD}^{+}$e macrófagos reforça essas características para o HIV, uma vez que reduz as defesas do organismo infectado ${ }^{(33)}$.

Em estudo descritivo publicado em 1990, 26 pacientes infectados pelo HIV foram avaliados para a presença de sintomas osteoarticulares, que ocorreram predominantemente sob a forma de artralgias, descritas em 65\% dos casos. As artralgias foram classificadas como poliarticular intermitente ( 5 casos), poliarticular persistente ( 3 casos), oligoarticular intermitente (7 casos) e monoarticular intermitente (2 casos). Dos 8 casos de comprometimento poliarticular, 5 apresentavam critérios para a FM e depressão(34).

No mesmo ano, Buskila et al. avaliaram 51 pacientes infectados pelo HIV (49 homens e 2 mulheres), comparados a 51 controles com artrite reumatóide (11 homens e 40 mulheres) e 50 controles com artrite psoriásica (29 homens e 21 mulheres), para o diagnóstico de FM (presença de pelo menos 10 dos 14 pontos de "fibrosite" considerados). Quinze pacientes infectados pelo HIV (29\%) e 12 controles com artrite psoriásica (24\%) apresentavam os critérios designados para FM. Dos controles com artrite reumatóide, vinte e nove pacientes (57\%) foram diagnosticados como fibromiálgicos $(p=0,001)$. Os autores não encontraram associação entre idade, duração da infecção pelo HIV, estágio da doença, uso da zidovudina e FM. Os autores testaram o nível de sensibilidade dos pontos dolorosos entre os pacientes do sexo masculino dos três grupos, não encontrando diferenças entre os mesmos ${ }^{(35)}$.

Medina Rodríguez et al., em 1993, realizaram um estudo observacional comparativo em 128 pacientes infectados pelo HIV e 130 controles com fatores de risco semelhantes, mas soronegativos, para o estudo das manifestações reumatológicas associadas à infecção pelo HIV. Os autores relataram a ocorrência de manifestações reumatológicas em 85 dos 128 pacientes infectados (66\%), e em apenas 6 indivíduos dos 130 controles $(4 \%)(p<0,0001)$. A FM foi diagnosticada em $5 \%$ dos pacientes HIV positivos ${ }^{(36)}$.

Trabalhos realizados no Brasil avaliaram as manifestações osteoarticulares associadas à infecção pelo HIV em pequenos grupos de pacientes, sem controles para comparação. As manifestações referentes a artralgias e mialgias foram freqüentemente relatadas, mas em nenhum trabalho foi citado o diagnóstico de $\mathrm{FM}^{(37-40)}$.

\section{VÍRUS C DA HEPATITE}

$\mathrm{O}$ vírus $\mathrm{C}$ da hepatite $(\mathrm{VCH})$ é um vírus de RNA esférico e envelopado, cuja estrutura, organização genômica e ciclo de replicação são similares aos de outros membros da família Flaviviridae, mas suficientemente distinto para merecer uma classificação em um novo gênero, o hepacivírus ${ }^{(41)}$.

A replicação do vírus ocorre nos hepatócitos, mas existem evidências de um tropismo para células $\mathrm{B}$, células $\mathrm{T}$ e monócitos circulantes, especialmente em hospedeiros com a infecção crônica ${ }^{(41)}$.

Dentre as manifestações extra-hepáticas da infecção crônica, destacam-se a crioglobulinemia mista essencial, a glomerulonefrite membranoproliferativa e a porfiria cutânea tarda. Em menor escala, a infecção pelo VCH tem sido associada a úlceras corneanas de Mooren, à síndrome de Sjögren, ao líquen plano e à fibrose pulmonar idiopática. Anticorpos antitireoidianos, tireodidite de Hashimoto e hipotireoidismo têm sido associados à infecção crônica pelo VCH em mulheres ${ }^{(41-45)}$.

Em editorial de 1996, Wener et al. chamam a atenção para o grande espectro de manifestações reumáticas associadas à infecção crônica pelo $\mathrm{VCH}$, como parte da síndrome de crioglobulinemia mista essencial, em suas formas completa e incompleta, e, também, como manifestações à parte do complexo dessa síndrome. Concluem que pacientes com os mais variados diagnósticos poderiam apresentar uma infecção crônica coexistente pelo vírus, e que os reumatologistas deveriam, a partir de então, implementar ao seu arsenal diagnóstico diferencial de rotina a avaliação do $\mathrm{VCH}$, especialmente para aqueles quadros de artrite crônica inflamatória ${ }^{(46)}$.

Em artigo do mesmo ano, Lovy et al. descrevem as manifestações reumatológicas em 19 pacientes infectados pelo $\mathrm{VCH}$, destacando o fato de que 15 deles preenchiam critérios para a artrite reumatóide. A FM foi diagnosticada em 6 desses pacientes $(31 \%)^{(14)}$.

Rivera et al., em 1997, avaliaram a associação entre FM e infecção crônica pelo VCH, em um estudo em 112 pacientes fibromiálgicos comparados a um grupo controle com o diagnóstico de artrite reumatóide, para a presença de infecção pelo $\mathrm{VCH}$, além da avaliação da presença de FM em 58 pacientes infectados pelo VCH comparados a um grupo controle de pacientes da clínica cirúrgica. A pre- 
sença de infecção pelo VCH determinada pelo ELISA foi detectada em 17 pacientes do grupo fibromiálgico (15,2\%) e em 6 pacientes com o diagnóstico de artrite reumatóide $(5,3 \%)(p<0,05)$. Os critérios diagnósticos de FM foram preenchidos por 6 pacientes com infecção crônica pelo VCH (10\%) e em apenas 1 paciente dos controles da clínica cirúrgica $(1,7 \%)(p<0,05)$. Os autores concluem que a infecção crônica pelo $\mathrm{VCH}$ deve ser sempre considerada nos pacientes com FM ${ }^{(15)}$.

Buskila et al. avaliaram as manifestações reumáticas de 90 pacientes com infecção crônica pelo VCH e encontraram como mais prevalentes a mialgia (24\%), as artralgias (9\%) e a artrite (4\%). A FM foi diagnosticada em 14 pacientes $(16 \%)$, dos quais 13 eram do sexo feminino ${ }^{(16)}$. Os autores compararam esses mesmos 90 pacientes a 128 controles sadios não infectados pelo VCH e a 32 pacientes cirróticos não infectados. Nos grupos controles, a FM foi diagnosticada em 1 paciente cirrótico (3\%) e em nenhum dos sadios $(\mathrm{p}<0,001)$. Os autores concluíram que existe uma elevada prevalência de FM em pacientes infectados pelo VCH, especialmente os do sexo feminino ${ }^{(17)}$.

Goulding et al., em 2001, avaliaram 67 pacientes infectados pelo VCH para os diagnósticos de fibromialgia, depressão e ansiedade, comparando os resultados a 25 controles sadios. O diagnóstico de FM foi detectado em 4 pacientes do sexo feminino infectadas pelo $\mathrm{VCH}(5 \%)$ e em nenhum dos controles. Depressão e ansiedade também foram mais prevalentes no grupo infectado. As pacientes fibromiálgicas apresentavam altos escores para depressão e ansiedade quando comparadas aos não-fibromiálgicos infectados e aos controles sadios ${ }^{(18)}$.

Poynard et al. avaliaram a grande coorte de Cacoub ${ }^{(38)}$, composta por 1.614 pacientes infectados pelo $\mathrm{VCH}$, para a presença de FM (diagnosticada pela associação de fadiga com artralgia ou mialgia) e a diagnosticaram em 302 desses pacientes $(19 \%)^{(19)}$.

Em artigo nacional recente, Loureiro et al. estudaram 84 pacientes infectados pelo $\mathrm{VCH}$ (50 homens e $34 \mathrm{mu}-$ lheres). A FM foi diagnosticada em 12 desses pacientes $(14,2 \%)$, dos quais 8 eram do sexo feminino. O diagnóstico de FM foi, neste estudo, detectado em 23\% das mulheres infectadas ${ }^{(47)}$.

\section{MISCELÂNEA}

O herpesvírus tipo 6 é um vírus de DNA da família Herpesviridae, originalmente denominado vírus linfotrópico humano de células B. Pode ser cultivado em vários tipos celulares, como células T, monócitos, macrófagos, megacariócitos e células embrionárias humanas. In vivo, o espectro de células em que pode replicar-se é bem amplo, embora, em sua grande maioria, as infectadas pelo herpesvírus tipo 6 apresentem marcadores de superfície de células $\mathrm{T}^{(48)}$.

Em estudo de 1992, Buchwald et al. não encontraram diferenças nos títulos de anticorpos contra o herpesvírus tipo 6 entre pacientes com a síndrome da fadiga crônica e controles, mas a replicação ativa do vírus foi demonstrada em 70\% dos pacientes e em apenas 20\% dos controles, sugerindo, assim, uma possível associação etiológica ${ }^{(49)}$.

Em 1996, em sua grande coorte de pacientes com fadiga crônica, Buchwald et al. não encontraram diferenças entre estes e controles para os títulos de anticorpos contra o herpesvírus tipo 6, o adenovírus, o vírus da rubéola e o citomegalovírus, dentre outras viroses avaliadas ${ }^{(31)}$.

Em 2001, Hechmann et al., em seu estudo para avaliação da FM e infecção virótica associada, segundo a forma de início da FM (aguda ou insidiosa), também não encontraram diferenças para os títulos de anticorpos contra o herpesvírus tipo 6, o vírus da rubéola e o citomegalovírus entre os pacientes fibromiálgicos, de acordo com a forma de início da síndrome, ou entre esses e controles sadios ${ }^{(32)}$.

Em 2000, Hechmann et al. avaliaram a presença do vírus borna em 18 pacientes fibromiálgicos com instalação aguda da síndrome, relacionada a um episódio prévio sugestivo de infecção. A presença do vírus foi testada pela PCR no soro e no líquido cérebro-espinhal, não sendo detectada em nenhum dos pacientes ${ }^{(50)}$. O vírus borna é um vírus de RNA relacionado ao gênero vesiculoviroses da família Rhabdoviridae, que produz infecção do sistema nervoso central em pássaros e primatas, tendo sido sugerida sua relação com doenças psiquiátricas em humanos, e também com a síndrome da fadiga crônica em pacientes japoneses ${ }^{(50,51)}$.

\section{CONCLUSÕES}

As infecções viróticas crônicas têm sido continuamente implicadas para uma possível relação etiopatogênica com a FM, muito embora as muitas pesquisas realizadas neste campo falhem em encontrar uma associação etiológica inequívoca.

Muitas são as premissas que justificam tal interesse: a) as manifestações clínicas comuns compartilhadas tanto pelos pacientes fibromiálgicos, especialmente a fadiga e a dor musculoesquelética, quanto em pacientes com infecções viróticas; b) os estudos em modelos animais, que sugeriram 
possíveis bases fisiopatológicas da sensibilização do sistema nervoso central a partir de exposição a toxinas exógenas, especialmente na presença de infecções viróticas ${ }^{(5)}$; $)$ estudos observacionais descritivos, que avaliaram a prevalência da FM em condições infecciosas específicas e, de modo contrário, a soroprevalência de algumas infecções viróticas crônicas em pacientes fibromiálgicos; e d) os estudos analíticos que, algumas vezes, apresentam resultados que sugerem a veracidade dessas associações.

Entretanto, apesar do enorme interesse por tais pesquisas, os resultados dos estudos analíticos são, em geral, imprecisos, e, na maioria das vezes, não confirmados em pesquisas subseqüentes. Uma rara exceção, aqui destacada, é o caso da possível associação entre a FM e a infecção pelo VCH, a qual vem sendo continuamente confirmada em estudos nos últimos anos ${ }^{(14-19)}$ (Tabela 1).

A despeito da incongruência dos resultados, as premissas plausíveis dessas associações devem ser ressaltadas, e as pesquisas de associações etiológicas devem ser encorajadas.

As questões metodológicas merecem ser, no entanto, mais bem discutidas. Alguns dos trabalhos compilados apresentam vieses importantes que comprometem a sua avaliação. Não interessa, no momento, fazer referências específicas, nem é finalidade deste artigo fazer uma análise crítica dos trabalhos compilados, mas é inconteste a necessidade de um maior refinamento do embasamento epidemiológico para tratar essa questão.

Além disso, os meios disponíveis para a detecção das infecções viróticas crônicas aguardam pela sempre contínua evolução da moderna virologia no que se refere à cada vez maior acurácia dos métodos diagnósticos.

Estudos cada vez mais refinados, sob o ponto de vista epidemiológico, que contam com métodos cada vez mais sensíveis e específicos, aliados à compreensão crescente dos

\section{REFERÊNCIAS}

1. Bennett RM: The Fibromyalgia syndrome: myofascial pain and chronic fatigue syndrome. In: Kelley WN, Harris Jr. ED, Ruddy S, Sledge CB, editors. Textbook of Rheumatology, 4th ed, Philadelphia, WB Saunders, 471-83, 1993.

2. MacFarlane GJ, Morris S, Hunt IM, et al: Chronic widespread pain in the community: the influence of psychological symptoms and mental disorder on healthcare seeking behavior. J Rheumatol 26 : 413-19, 1999.

3. Wolfe F, Ross K, Anderson J, Russell IJ, Hebert L: The prevalence and characteristics of fibromyalgia in the general population. Arthritis Rheum 38: 19-28, 1995.

4. Croft P, Rigby AS, Boswell R, Schollum J, Silman A: The prevalence of chronic widespread pain in the general population. J Rheumatol 20:710-13, 1993.
TABELA 1

RESUMO DOS ESTUDOS DE ASSOCIAÇÃO ENTRE Fibromialgia E VIROSES RELACIONADAS

\begin{tabular}{lcc}
\hline Viroses & $\begin{array}{c}\text { Associação com } \\
\text { a fibromialgia }\end{array}$ & Referências \\
\hline Epstein-Barr & - & 21,22 \\
\hline Parvovírus B19 & $?$ & 23 \\
& $?$ & 26 \\
Coxsackie B & - & $25,27,28$ \\
& $?$ & 30,32 \\
HIV & - & 31 \\
\hline VCH & $?$ & 36 \\
& - & 35 \\
Herpesvírus tipo 6 & $?$ & 14 \\
\hline Adenovírus & + & $15,17,18$ \\
Rubéola & $?$ & 49 \\
\hline Citomegalovírus & - & 31,32 \\
\hline a associaça querna & - & 50 \\
\hline
\end{tabular}

? associação questionada; - ausência de associação; + associação detectada.

exatos mecanismos biológicos envolvidos no processo de adoecimento, poderão fornecer resultados cada vez mais conclusivos e definitivos sobre a questão.

\section{AGRADECIMENTOS}

Os autores agradecem à professora de Língua Portuguesa, Marilza Gláucia Dias Ribeiro, pela correção final do manuscrito. 
10. Okifuji A, Turk DC, Sherman JJ: Evaluation of the relationship between depression and fibromyalgia syndrome: why aren't all patients depressed? J Rheumatol 27:212-19, 2000.

11. Gladman DD, Urowitz MB, Gough J, MacKinnon A: Fibromyalgia is a major contributor to quality of life in lupus. J Rheumatol 24 : 2145-48, 1997.

12. Dermody TS, Tyler KL: Introduction to viruses and viral diseases. In: Mandell GL, Bennett JE, Dolin R, editors. Principles and practice of infectious diseases, 5th ed, Philadelphia, Churchill Livingstone, 1536-52, 2000.

13. Kalden JR: Viral arthritis. In: Klippel JH, Dieppe PA, editors. Rheumatology, 1th ed, London, Mosby, 6.1-6.8, 1994.

14. Lovy MR, Starkebaum G, Uberoi S: Hepatitis C infection presenting with rheumatic manifestations: a mimic of rheumatoid arthritis. J Rheumatol 23: 979-83, 1996.

15. Rivera J, De Diego A, Trinchet M, Garcia Monforte A: Fibromyalgia associated hepatitis C virus infection. Br J Rheumatol 36:981-85, 1997.

16. Buskila D, Shnaider A, Neumann L et al: Musculoskeletal manifestations and autoantibody profile in 90 hepatitis $\mathrm{C}$ virus infected Israeli patients. Semin Arthritis Rheum 28:107-13, 1998.

17. Buskila D, Shnaider A, Neumann L, Zilberman, Hilzenrat N, Sikuler E: Fibromyalgia in hepatitis $\mathrm{C}$ virus infection. Another infectious disease relationship. Arch Intern Med 157:2497-500, 1997.

18. Goulding C, O'Connell P, Murray FE: Prevalence of fibromyalgia, anxiety and depression in chronic hepatitis $\mathrm{C}$ virus infection: relationship to RT-PCR status and mode of acquisition. Eur J Gastroenterol Hepatol 13:507-11, 2001.

19. Poynard T, Cacoub P, Ratziu V et al: Fatigue in patients with chronic hepatitis C. J Viral Hepatitis 9:295-303, 2002.

20. Feldman C: Mononucleose infecciosa. In: Veronesi R. Doenças infecciosas e parasitárias, 7a ed, Rio de Janeiro, Guanabara Koogan S.A., 194-99, 1982.

21. Buchwald D, Goldenberg DL, Sullivan JL, Komaroff AL: The "chronic, active Epstein-Barr virus infection" syndrome and primary fibromyalgia. Arthritis Rheum 30:1132-36, 1987.

22. Whelton CL, Salit I, Moldofsky H: Sleep, Epstein-Barr virus infection, musculoskeletal pain, and depressive symptoms in chronic fatigue syndrome. J Rheumatol 19:939-43, 1992.

23. Feldman D, Atra E, Goldenberg J: Vírus de Epstein-Barr e síndrome de fibromialgia. Rev Bras Reumatol 23:110-20, 1992.

24. Serra CRB, Sztajnbok FR: Manifestações reumáticas associadas à parvovirose. Rev Bras Reumatol 38:221-28, 1998.

25. Berg AM, Naides SJ, Simms RW: Established fibromyalgia syndrome and parvovirus B19 infection. J Rheumatol 20:1941-43, 1993.

26. Leventhal LJ, Naides SJ, Freundlich B: Fibromyalgia and parvovirus infection. Arthritis Rheum 10:1319-24, 1991.

27. Branco JC, Tavares V, Abreu I, Humbel RL: Infecção viral e fibromialgia. Acta Med Port 7:337-41, 1994.

28. Ilaria RL, Komaroff AL, Fagioli LR, Moloney WC, True CA, Naides SJ: Absence of parvovirus B19 infection in chronic fatigue syndrome. Arthritis Rheum 38:638-41, 1995.

29. Góes P, Liberto MIM, Ono IPC, Von Hubinger MG: Coxsackioses. In: Veronesi R. Doenças infecciosas e parasitárias, 7a ed, Rio de Janeiro, Guanabara Koogan S.A.,76-87, 1982.
30. Nash P, Chard M, Hazleman B: Chronic coxsackie B infection mimicking primary fibromyalgia. J Rheumatol 16:1506-8, 1989.

31. Buchwald D, Ashley RL, Pearlman T, Kith P, Komaroff AL: Viral serologies in patients with chronic fatigue and chronic fatigue syndrome. J Med Virol 50:25-30, 1996.

32. Wittrup IH, Jensen B, Bliddal H, Danneskiold-SamsÆe B, Wiik A: Comparison of viral antibodies in 2 groups of patients with fibromyalgia. J Rheumatol 28:601-3, 2001.

33. Streicher HZ, Reitz JR., MS, Gallo RC: Human immunodeficiency viruses. In: Mandell GL, Bennett JE, Dolin R, editors. Principles and practice of infectious diseases, 5th ed, Philadelphia, Churchill Livingstone, 1874-87, 2000.

34. Simms RW, Ferrante N, Craven DE \& the AIDS Clinical Research Team: High prevalence of fibromyalgia syndrome (FMS) in human immunodeficiency virus type 1 (HIV) infected patients with polyartralgia [abstract]. Arthritis Rheum 33 (Suppl): S136, 1990.

35. Buskila D, Gladman DD, Langevitz P, Urowitz S, Smythe HA: Fibromyalgia in human immunodeficiency virus infection. J Rheumatol 17:1202-6, 1990.

36. Medina Rodríguez F, Hermida C, Jara LJ, Irigoyen L, Cabido M, Miranda Limón JM: Impacto del virus de inmunodeficiencia humana sobre manifestaciones reumatológicas en poblaciones de alto risco. Rev Mex Reumatol 8:225-34, 1993.

37. Gulko OS, Costa S, Tourinho TF, et al: Alterações músculoesqueléticas em pacientes com SIDA. Rev Bras Reumatol 31: 141-3, 1991.

38. Verztman JF, Leite NH, Guimarães SJ, Goldfarb M, João EC: SIDA (AIDS) e manifestações reumáticas. Estudo de 15 casos. Rev Bras Reumatol 34:129-34, 1994.

39. Oliveira RL, Salgado MCF, Silva AM, et al: Manifestações reumáticas em pacientes infectados pelo HIV. Rev Bras Reumatol 38: 378, 1998.

40. Ferreira GA: Manifestações reumáticas na síndrome da imunodeficiência adquirida. In: Moreira C, Carvalho MAP. Reumatologia - Diagnóstico e tratamento, 2a ed, Rio de Janeiro, MEDSI, 673-87, 2001.

41. Thomas DL, Lemon SM: Hepatitis C. In: Mandell GL, Bennett JE, Dolin R, editors. Principles and practice of infectious diseases, 5 th ed, Philadelphia, Churchill Livingstone, 1736-60, 2000.

42. Staub HL: Vírus C da hepatite, manifestações sistêmicas e o reumatologista. Rev Bras Reumatol 38:139-46, 1998.

43. Daghestani L, Pomeroy C: Renal manifestations of hepatitis C infection. Am J Med 106:347-54, 1999.

44. Cacoub P, Poynard T, Ghillani P, et al: Extrahepatic manifestations of chronic hepatitis C. Arthritis Rheum 42:2204-12, 1999.

45. Killemberg PG: Extrahepatic manifestations of chronic hepatitis C. Semin Gastrointest Dis 11:62-8, 2000.

46. Wener MH, Johnson RJ, Sasso EH, Gretch DR: Hepatitis C virus and rheumatic disease (Editorial). J Rheumatol 23:953-9, 1996.

47. Loureiro M, Belloto E, Christmann RM, et al: Prevalência de fibromialgia em pacientes infectados com o vírus da hepatite C. Rev Bras Reumatol 42:37-41, 2002.

48. Straus SE: Human herpesvirus types 6 and 7. In: Mandell GL, Bennett JE, Dolin R, editors. Principles and practice of infectious diseases, 5th ed, Philadelphia, Churchill Livingstone,1613-18, 2000. 
49. Buchwald D, Cheney PR, Peterson DL, et al: A chronic illness characterized by fatigue, neurologic and immunologic disorders, and active human herpesvirus type 6 infection. Ann Inter Med 116: 103-13, 1992.

50. Bleck TP, Rupprecht CE: Rabies virus. In: Mandell GL, Bennett JE, Dolin R, editors. Principles and practice of infectious diseases, 5th ed, Philadelphia, Churchill Livingstone, 1811-20, 2000.
51. Wittrup IH, Christensen LS, Jensen B, Danneskiold-Samse B, Bliddal H, Wiik A: Search for borna disease virus in Danish fibromyalgia patients. Scand J Rheumatol 29:387-90, 2000. 